\title{
METAMORFOSES DA PREVENÇÃO: prevenindo condutas de risco na França
}

\section{(1) Tiago Hyra Rodrigues}

Centro Brasileiro de Análise e Planejamento - CEBRAP. São Paulo, SP, Brasil.

E-mail: tiagohyra@cebrap.org.br

DOI: $10.1590 / 3710801 / 2022$

\begin{abstract}
Resumo: $\bigcirc$ artigo descreve os discursos e práticas de profissionais e instituições que utilizam tecnologias sociais de prevenção inspiradas pela abordagem denominada, na França, "prevenção de condutas de risco". No campo teórico, o texto aborda os processos de subjetivação envolvidos em tal prevenção, a aplicação do conceito de risco ao campo preventivo, e as tensões entre este campo e o controle social. No campo descritivo, procura retraçar possíveis origens e a trajetória de institucionalização das políticas preventivas francesas baseadas nesta abordagem, assim como das técnicas e metodologias utilizadas pelas instituições em seu trabalho junto a usuários de substâncias psicoativas e a jovens considerados "em situação de risco ou de vulnerabilidade social". Finalmente, apresenta uma descrição etnográfica das estratégias, discursos e tecnologias sociais envolvidas nas tentativas de evitar a entrada de jovens no tráfico de drogas.
\end{abstract}

Palavras-chave: prevenção; risco; políticas públicas; França; tráfico.

\section{PREVENTION METAMORPHOSES: preventing risky behavior in France}

\begin{abstract}
The article describes the discourses and practices of professionals and institutions that employ preventive social technologies inspired by the approach called "risk behavior prevention" in France. Theoretically, the text addresses the subjectivation processes involved in such prevention, the application of the concept of risk in the preventive field, and the tensions between this field and social control. It also seeks to trace possible origins and the institutionalization trajectory of French preventive policies based on this approach, as well as the techniques and methodologies used by the institutions in their work among psychoactive substances users and young people considered "at risk" or "socially vulnerable". Finally, it presents an ethnographic description of the strategies, discourses and social technologies involved in attempts to prevent young people from entering the drug trade.
\end{abstract}

Keywords: prevention; risk; public policies; France; drug trafficking. 


\section{Introdução}

Delinquência, criminalidade, violência e tráfico de substâncias são problemas sociais muito estudados nas ciências humanas. Minhas pesquisas, particularmente, se dirigem à análise de estruturas, dispositivos, discursos, práticas e agentes que se dedicam à prevenção destes problemas. Em pesquisas anteriores (Rodrigues, 2011; 2017), descrevi estratégias educacionais de prevenção da violência e da criminalidade empregadas por ONGs brasileiras.

Ao chegar na França, em 2013, para pesquisar a "prevenção da violência", imaginava encontrar um campo semelhante ao brasileiro, com o qual pudesse estabelecer comparações e traçar paralelos. Para minha surpresa, na França não se utiliza tal termo. Talvez eu exagere: lá, quando se fala de prevenção da violência, a referência é ou a guerra e terrorismo, ou a operações especiais da polícia - por exemplo, para prevenir confrontos entre torcedores de equipes de futebol rivais. Nada semelhante ao trabalho conduzido pelas ONGs brasileiras, ao menos com esta denominação. No final de 2014, porém, recebi um convite para o encontro "Face às condutas de risco: os caminhos criativos da prevenção", organizado por algo chamado Missão Metropolitana de Prevenção de Condutas de Risco. Entre palestras teóricas, oficinas de boas práticas preventivas e discussões sobre competências psicossociais e autoestima, pude ver a multiplicidade dos atores deste campo e a amplitude dos temas abarcados - e, consequentemente, do próprio conceito de condutas de risco.

Neste artigo, tento descrever o campo da "prevenção de condutas de risco" na França, situando-o na intersecção de diversos outros - como saúde, educação, segurança, assistência, humanitarismo etc. Apesar de tentar fazer um relato mais geral sobre as condutas de risco, minha atenção estará voltada sobretudo para as tecnologias sociais ${ }^{1}$ de prevenção de condutas de risco que procuram evitar o engajamento de jovens no tráfico de substâncias, na delinquência e criminalidade, ou seja, na prevenção de comportamentos que trazem riscos sociais, e não apenas sanitários. Além disso, pretendo descrever como o conceito de risco "colonizou" o campo da prevenção dos problemas sociais, tornando-se fundamento de intervenções e políticas públicas. Para tanto, será necessário discutir o que são as condutas de risco - assim como o que é risco-, relatar um pouco da história recente da prevenção dos problemas sociais na França, mostrar alguns dos atores e instituições que compõem este campo, e detalhar suas estratégias e intervenções.

A metodologia desta pesquisa combinou trabalho de campo etnográfico e análise discursiva, tendo como técnicas a observação (participante, quando foi possível), a elaboração de diários de campo, a realização de entrevistas abertas, ${ }^{2}$ a coleta de histórias de vida e a análise documental (atas, estatutos, publicações, legislação). Os dados foram sistematizados com o auxílio do software Atlas.ti.

O trabalho de campo foi realizado entre 2014 e 2016, em sete instituições localizadas na região metropolitana de Paris: Association Française pour la Réduction des Risques AFR; Auto-Support des Usagers de Drogues - ASUD; Association Techno+; Association Vie et Cité - AVeC; Maison des Copains de la Villette - MCV; Association Gaïa Paris - AGP; e Mission Métropolitaine de Prévention de Conduites à Risques - MMPCR. Três delas (AFR, ASUD e AGP) trabalham com usuários de substâncias psicoativas; duas ( $M C V$ e AVeC) são "clubes de prevenção especializada" e atuam junto a crianças e adolescentes; a Techno+ intervém em ambientes festivos; e a MMPCR é uma estrutura mista da prefeitura de Paris e

\footnotetext{
Tecnologias sociais são métodos, processos e técnicas desenvolvidos e/ou aplicados na interação com a população e apropriados por ela. São utilizados para solucionar problemas sociais, com impacto comprovado por sua replicabilidade (Dagnino, 2014).

2 Todos/as os/as entrevistado/as autorizaram a divulgação de seus depoimentos para fins acadêmicos.
} 
do Conselho Geral de Seine-Saint-Denis, encarregada de elaborar e disseminar políticas públicas de prevenção.

As dinâmicas de atuação destas instituições não permitiram o trabalho de campo imersivo no cotidiano de todas. Como durante a pesquisa AFR e ASUD funcionavam apenas de forma virtual, a análise se baseia na documentação presente em seus sites ${ }^{3} \mathrm{e}$ publicações, e nas extensas entrevistas com Anne Coppel e Fabrice Olivet, fundadores e diretores da AFR e da ASUD, respectivamente. Na MMPCR, a observação foi realizada em seus eventos - debates, conferências, oficinas, formações - e visitas à sede, em Pantin. Nas demais instituições, com maiores ou menores limitações, realizei trabalho de campo etnográfico e observação participante. Na AGP, pude acompanhar saídas de campo dois dias por semana; visitei a $\mathrm{AVeC}$ uma vez por semana; na $\mathrm{MCV}$, atuei como voluntário e acompanhei o trabalho de rua dos profissionais às quartas e aos sábados; estive com a equipe da Techno+ em diversas festas e eventos, e em sua preparação.

Realizei 27 entrevistas e/ou coletas de histórias de vida, de uma a quatro horas de duração cada uma, tanto com dirigentes quanto com profissionais envolvidos na interação com o público. Com exceção de Olivet, que é historiador, e de uma enfermeira e um psiquiatra da AGP, todos/as eram educadores/as, psicólogas/os, trabalhadores/as sociais ou sociólogas/os. Em termos de gênero, as porcentagens de homens e mulheres nas instituições eram quase equivalentes, com propensão a um número maior de mulheres em cargos diretivos. Na pesquisa, procurei replicar este equilíbrio, entrevistando catorze mulheres e treze homens. $\mathrm{O}$ objetivo era descrever e analisar os discursos e práticas destes atores à luz da literatura socioantropológica sobre temas como risco, prevenção, controle e subjetivação, tentando acessar a forma como justificam suas ações e estruturam sua prática.

\section{Risco e prevenção}

Muitos conceitos foram acionados para tentar dar conta do engajamento dos jovens no "mundo do crime" ou "nas drogas", como marginalidade e desvio (Becker, 1985; Downes \& Rock, 1988). Apesar do termo nem de longe ser novo - teria surgido com a teoria dos jogos na Renascença (Bernstein, 1996) -, nas últimas décadas ganhou proeminência, tanto na academia quanto entre profissionais e militantes, o conceito de risco. A princípio, a ideia de risco era neutra, uma medida de incerteza; tratava da probabilidade de perdas e de ganhos em uma aposta. Mas em seu desenvolvimento histórico, ganhou novos usos, do cálculo de seguros marítimos à mensuração dos "riscos sociais" que embasavam as políticas do Estado-providência (Ewald, 1986). Também é um conceito importante na área da saúde e na medicina, em especial na epidemiologia, em que o risco se torna indissociável da prevenção (Jessor, 1991). Em epidemiologia, o risco - de contrair uma doença infecciosa, digamos - representa uma realidade objetiva e mensurável, passível de cálculo. Os indicadores de risco (como a morbidade, ou taxa de portadores de uma doença em relação à população total estudada) transformam incertezas em probabilidades. Com base nelas, são definidos os locais, indivíduos e grupos mais suscetíveis, e elaboradas formas de intervenção e prevenção.

Prevenção é uma atitude ou conjunto de medidas que têm como objetivo evitar algum acontecimento - ou reduzir suas consequências, quando é impossível evitá-lo. O modelo "clássico" de prevenção em saúde é dividido em prevenção primária, secundária e terciária. A primária é voltada para o público mais amplo, que não tem ou não manifestou uma doença; em geral através de informação e educação, visa evitar a exposição de um

\footnotetext{
${ }^{3}$ Disponíveis, respectivamente, em: https://a-f-r.org/ e http://www.asud.org/.
} 
indivíduo/grupo a um fator de risco antes que um mecanismo patológico se desenvolva. A secundária busca o diagnóstico precoce de um problema em um indivíduo ou população com alto risco de desenvolvê-lo, de modo a facilitar o tratamento imediato e evitar consequências mais sérias. A terciária visa reduzir os malefícios causados por uma doença e evitar recaídas, buscando a reintegração social do indivíduo acometido. Nestas definições, podemos perceber como risco e prevenção estão interconectados, além da aura de probabilidade negativa que o conceito de risco assume neste campo.

O conceito de risco aparece de maneira mais intensiva nos debates socioantropológicos a partir dos anos 1970-80, principalmente nas discussões sobre os riscos tecnológicos, a financeirização do capital e a "modernidade reflexiva" (Beck, 1992). Já fundamental para as ciências atuariais, a epidemiologia e a economia, gradativamente o conceito passou a permear campos tão diversos quanto a psicologia, o ambientalismo, o trabalho social e o lazer (Douglas, 1992; LeBreton, 1991, 2002). No rastro desta difusão, o conceito de risco com o qual lidamos hoje na arena pública tem pouca relação com sua versão renascentista. Para Douglas (1992), "risco" agora se refere apenas aos possíveis resultados negativos:

"'Risco' é a probabilidade de um evento, combinada com a magnitude das perdas e ganhos que ele acarretará. No entanto, nosso discurso político degrada a palavra. De uma complexa tentativa de reduzir a incerteza, tornou-se um floreio decorativo para a palavra 'perigo'" (Douglas, 1992:40). ${ }^{4}$

Além disso, para Douglas, o risco, revestido de uma aura mais científica que o perigo, é um poderoso instrumento para designar culpas e culpados, uma estratégia retórica que permite julgamentos morais e controle social de comportamentos não-conformes, reforçando a estigmatização e a culpabilização de indivíduos/populações.

Para Rabinow (2010), o risco não é mais o resultado de perigos específicos, colocados pela presença de uma pessoa ou de um grupo, mas uma composição de "fatores" impessoais que tornam algo provável. A prevenção não é, portanto, a vigilância do indivíduo, mas de ocorrências prováveis de doenças, anomalias ou comportamentos desviantes que devem ser minimizados e de comportamentos sadios que devem ser maximizados. Este novo modelo antecipa possíveis "anomalias" através da identificação estatística de indivíduos/grupos que partilham características ou comportamentos, reagrupando-os de uma forma que não apenas os descontextualiza de seu ambiente social, mas que também é "não-subjetiva em um duplo sentido: é produzida objetivamente e não se aplica ao sujeito em nenhum dos sentidos clássicos deste termo"(Rabinow, 2010:30).

Bailleau (2011) lembra que a caracterização (ou, pior, a determinação estatística) de sujeitos ou populações como "vulneráveis" ou "em risco" pode se revelar uma justificativa para políticas de intervenção e controle sobre populações julgadas desviantes ou "perigosas". Assim, quando se fala de prevenção do risco, não se trata de dirimir os riscos aos quais estas pessoas e populações estão submetidas, mas sim de colocar em funcionamento um dispositivo de assistência associado a outras formas de controle. Trata-se de gerir o risco que elas representam para as demais.

Esta literatura nos aponta possíveis problemas na aplicação do conceito de risco às políticas públicas de prevenção, como recair naquilo que Castel (1981) denomina "administração tecnocrática das diferenças". Sua aplicação em uma gestão "de cima para baixo" de populações estatisticamente mais predispostas a tais comportamentos teria um potencial "dessubjetivador", estigmatizando sujeitos e reforçando o controle social. No entanto, os discursos dos profissionais alinhados com a abordagem da "prevenção de condutas de risco" com quem tive contato vão no sentido oposto ao apontado pela literatura. De acordo com eles, suas ações preventivas buscam colocar o público-alvo no centro da elaboração de propostas preventivas, indo ao seu encontro, ouvindo

\footnotetext{
${ }^{4}$ Todas as citações originalmente em francês ou inglês foram traduzidas pelo autor.
} 
seus problemas e construindo, conjuntamente e idealmente em pé de igualdade, as intervenções apropriadas.

Nem tanto ao mar, nem tanto à terra. Fassin (2010) argumenta que as políticas públicas francesas dirigidas ao combate de problemas sociais junto a populações "vulneráveis" ou "em risco" são baseadas em sentimentos morais, como a compaixão, e estão permeadas por paradoxos e ambiguidades. Para ele, as políticas de governo para a população vulnerável se empenham em "aliviar o sofrimento", mas se afastam da intervenção sobre suas causas. Fassin afirma que há nestas políticas da compaixão uma representação ambígua dos sujeitos, vistos ao mesmo tempo como riscos para os demais e como pessoas sofrentes, vítimas de uma sociedade desigual e de um destino que não controlam. As soluções daquilo que Fassin chama "governo humanitário" 5 para este sofrimento social apresentam a mesma ambiguidade, alternando e mesclando políticas preventivas e repressivas, cuidado e controle social, solidariedade e desigualdade, dominação e ajuda - articulando lógicas securitárias de disciplinamento e controle com lógicas humanitárias de intervenção social. Fassin descreve como esses discursos e práticas, no lugar de promover intervenções em problemas coletivos e estruturais, elicitam ações de higiene social e legitimam práticas de governo que tendem a traduzir problemas sociais na linguagem da saúde mental (muitas vezes remetendo aos indivíduos a responsabilidade por tais problemas), silenciando as causas sociais dos problemas que afirmam combater. Se, desta forma, Fassin (2010:61) afirma que o sofrimento social é uma construção política, podemos dizer o mesmo sobre o risco.

De outro lado, é importante resgatar uma concepção de risco que inclua o fato de que, quando se assume um risco, o objetivo é a satisfação de uma necessidade ou aspiração, sendo que no processo de buscá-la existe a probabilidade de ocorrerem efeitos indesejados. Esta perspectiva acrescenta tanto a dimensão de escolha e decisão envolvida quanto o fato de que assumir riscos pode trazer benefícios, prazer, satisfação. Sem isso, torna-se extremamente difícil entender o que motiva tais condutas (Katz, 1988); e sem a compreensão das motivações, o trabalho preventivo não teria nenhum sentido. Mas como prevenir riscos comportamentais, e como os discursos sobre o risco afetam a prevenção? Quais métodos, técnicas e tecnologias sociais têm surgido neste campo?

A partir dos anos 1990, um conjunto de estratégias preventivas de problemas sociais ganhou visibilidade: a abordagem intitulada "prevenção de condutas de risco". O conceito de condutas de risco foi utilizado para indicar um conjunto de comportamentos considerados "perigosos": abuso de substâncias (lícitas ou ilícitas), delinquências diversas, tráfico, agressões, sexo não-seguro, uso problemático das redes sociais, adição a jogos, consumo compulsivo, prostituição, suicídio e tentativas e muitos outros (Jessor, 1991; LeBreton, 2002). Apesar do conceito de condutas de risco ser uma forma excessivamente vaga de categorizar uma vasta gama de comportamentos discrepantes sob um mesmo rótulo "guarda-chuva", tal agrupamento desperta interesse pela forma como tem guiado um conjunto de intervenções destinadas a prevenir tais condutas.

Sem pretender realizar uma revisão exaustiva da literatura sobre condutas de risco, enfatizo que ela sublinha a ambiguidade e a polissemia do conceito. LeBreton (1991) distingue entre condutas de risco socialmente valorizadas (como esportes radicais) e moralmente negativas (delinquência, abuso de substâncias etc.). A discussão teórica sobre estas últimas acolhe desde concepções que as percebem como comportamentos "desviantes" de indivíduos que devem ser cuidados, geridos e controlados, até concepções que as apresentam como modalidades de comportamento que integram certas dinâmicas de

\footnotetext{
Fassin (2010:8) denomina governo humanitário o desenvolvimento dos sentimentos morais, como compaixão ou solidariedade, nos dispositivos e ações destinados a administrar, regular e favorecer a existência dos seres humanos, o que inclui a ação do Estado, mas a ultrapassa.
} 
sociabilidade. Neste quadro, as condutas de risco seriam recursos culturais para a (auto) construção identitária e para o reconhecimento social: fornecem visibilidade, dinheiro, prestígio aos olhos dos pares, o prazer da transgressão, o sentimento de ser capaz (Katz, 1988). Seriam, assim, formas de comportamento que podem auxiliar o indivíduo a encontrar sentido e a se sentir, finalmente, sujeito; seriam modos de alcançar uma auto-subjetivação, ainda que não aquela que a sociedade deseja (Wieviorka, 2012).

A literatura sobre as condutas de risco acentua tanto os perigos inerentes a elas quanto o potencial de sedução e de atração social trazido por sua capacidade de gerar visibilidade e reconhecimento. Tal aura de perigo e sedução estimula esforços preventivos. Como as condutas de risco são hoje enfrentadas na França, e como sua prevenção tornou-se uma política pública?

\section{Pequena história da institucionalização de uma política preventiva}

Na França pude identificar, tanto no campo associativo quanto no das políticas públicas, um conjunto de intervenções dedicado à prevenção do engajamento dos jovens "no crime" e "nas drogas". Estas intervenções se apresentam sob a forma de um modelo de prevenção que combina, de um lado, metodologias oriundas da psicologia social e da psicopedagogia, que valorizam tecnologias sociais de desenvolvimento das chamadas competências psicossociais e da autoestima; e, de outro, metodologias preventivas originárias da saúde pública e do trabalho preventivo junto aos usuários de drogas - a abordagem da harm reduction, conhecida em português como redução de danos. A interpenetração e a complementaridade entre estes modos de intervenção preventiva deram origem ao conjunto de tecnologias sociais do modelo "prevenção de condutas de risco", que combina elementos dos anteriores para tentar prevenir problemas sociais.

Para entender como este modelo adquiriu proeminência, inscreveu-se em um quadro institucional legítimo e tornou-se fundamento de políticas públicas, apresento um pouco do cenário jurídico/legal e do desenvolvimento recente das práticas preventivas na França, enfatizando as disposições relativas à prevenção "das drogas" e da delinquência. Sem espaço para retraçar toda esta história (poderíamos retroceder até a criação do Hôpital Général), ${ }^{6}$ tento reconstruir alguns momentos importantes a partir de documentos e entrevistas, principalmente com Anne Coppel (AFR), Vincent Benso (Techno+), Fabrice Olivet (ASUD), Marie-Thérèse Gaudier e Manuel Chambrouty (MMPCR), Enrique Iglesias (AVeC) e Yann LeCouturier (MCV).

Em 1969, segundo Benso (2016), houve na França um intenso "pânico moral" a respeito das drogas, após uma série de mortes por overdose amplamente divulgadas na mídia. Tal pânico teria levado, no ano seguinte, ao surgimento da Loi 70,7 que estabelece dois tipos de resposta legal para o usuário de substâncias ilícitas, a médica e a penal - ou seja, o considera ao mesmo tempo como doente e delinquente -, além de definir penas pesadas para o tráfico. Ressalte-se a ênfase na repressão e a quase completa ausência de uma política preventiva, restrita à mais banal das prevenções primárias: "Diga não às drogas".

Em 1972, o Estado francês reconhece a necessidade da prevenção dirigida aos jovens, através de um decreto que regula a criação dos clubes de prevenção especializada (como MCV e AVeC). Conhecida como PS, a Prévention Spécialisée tem como objetivo "romper o isolamento e restaurar o vínculo social de jovens em vias de marginalização" e deve ser implantada "onde os fenômenos de inadaptação social são particularmente

6 O Hôpital Général fazia parte de um conjunto de estabelecimentos fundados no século XVII na França com o objetivo de confinar pobres, doentes, delinquentes e indigentes.

7 Lei n. 70-1320 de 31 dez.1970. 
desenvolvidos" (Dases, 2011:4). Criada para atender jovens entre onze e 25 anos, ela pode se dirigir aos mais novos (a AVeC atende crianças a partir de seis anos). A PS é caracterizada pelo mandato não-nominativo e pela livre adesão - não é um juiz que determina que um jovem deve receber a atenção do educador; as atividades não são obrigatórias e os jovens escolhem participar ou não -, pelo respeito do anonimato dos jovens, pela articulação de parcerias (com a escola ou o setor de inserção profissional) e pela não-institucionalização das práticas (ações que funcionam em um momento ou local podem não ser adequadas em outros). Seus profissionais tipicamente vão ao encontro dos jovens e buscam estabelecer vínculos relacionais que possibilitem o trabalho preventivo.

Apesar destas medidas, segundo Coppel (2016) e Olivet (2016), no final dos anos 1970 o número de usuários de substâncias ilícitas cresceu muito, com a difusão massiva da heroína entre a população mais pobre e nos quartiers sensibles. Tal quadro se tornou dramático, na década de 1980, com a epidemia de HIV-Aids, que atingiu duramente os usuários de drogas injetáveis, obrigando a prevenção francesa a se reinventar (Cavalcanti, 2001). Uma catástrofe sanitária, agravada pela política repressiva da "guerra às drogas" e pela proibição de venda e distribuição de seringas pela Loi 70.

O final dos anos 1980 e o início dos 1990 foram de mobilização e militância. Diversas associações e entidades foram fundadas com o objetivo de acolher os usuários, mas também de pressionar o Estado para que agisse. Em 1987 surge a pioneira associação Espoir Goutte d'Or (EGO), ${ }^{8}$ no norte de Paris, com o objetivo de oferecer um cuidado humanizado (sanitário e social) aos usuários. Em 1990, a ONG humanitária Médecins du Monde lança um programa de troca de seringas, na ilegalidade. Buscando soluções, associações, movimentos e militantes compilam práticas preventivas comprovadamente eficazes. Nesta busca, chegaram ao conceito de harm reduction, um conjunto de políticas sanitárias projetado para reduzir as consequências negativas associadas a diversos comportamentos. Suas estratégias foram utilizadas inicialmente para limitar a transmissão de infecções, como hepatites ou HIV, entre usuários de substâncias injetáveis, e depois estendidas a um cuidado mais global com a saúde dos usuários, enfatizando as noções de autonomia, responsabilidade e participação cidadã nas políticas públicas (INSERM, 2010). Segundo Coppel, os resultados alcançados pela redução de danos na Holanda e na Inglaterra (diminuição de overdoses, limitação de infecções, queda da mortalidade) estimularam a adoção de seus (polêmicos) métodos em terras francesas.

Na Grã-Bretanha, a redução dos riscos ou danos ligados ao uso de drogas se inscreveu em uma política de saúde pública fundada na aceitação do uso de drogas. Cuidado e prevenção foram redefinidos em função de uma hierarquia de riscos: é melhor não consumir drogas, mas se você consome, é melhor consumir as drogas menos perigosas e da forma menos perigosa possível; é melhor não injetar, mas se você continua a se injetar, é melhor usar uma seringa estéril, e assim por diante. (Coppel, 2002, p.13)

Com tais princípios em mente, os profissionais e militantes multiplicaram equipes de rua, ações de albergamento e de inserção social e profissional, facilitando o acesso a direitos (documentos, saúde, assistência social, moradia) e tentando estimular a sociabilidade (grupos de autossuporte, atividades artísticas e esportivas nos centros de acolhimento, reaproximação com familiares). Além disso, inspirados no chamado outreach ${ }^{9}$ (em francês aller-vers, "ir em direção a"), privilegiaram o contato direto com os usuários, seus problemas e condições sociais, visando compreender seu estilo de vida e se valendo de sua experiência prática para elaborar ações e intervenções:

\footnotetext{
${ }^{8}$ As histórias desta associação e de sua fundadora, Lia Cavalcanti, assim como da AFR e de sua fundadora, Anne Coppel, merecem mais espaço do que este artigo pode oferecer. Espero poder voltar a elas em breve.

9 Outreaché um conjunto de abordagens que busca fornecer serviços ou assistência à população que, de outra forma, não teria acesso a eles (Rhodes, 1996).
} 
Nos demos conta de que não podíamos fazer uma prevenção eficaz sem integrar a cultura específica dos modos de uso e dos riscos assumidos. A epidemia do HIV recolocou os usuários no centro da intervenção social, sendo que antes eles eram objetos. (Cavalcanti, 2001, p.110)

No início dos anos 1990, a abordagem da harm reduction estava relativamente consolidada entre os agentes de campo e militantes. No entanto, a política oficial continuava baseada na repressão e na prevenção primária, que muitas vezes beirava o ridículo: Benso lembra um vídeo que mostrava uma babá usando cocaína e colocando o bebê sob seus cuidados no micro-ondas. Paralelamente, policiais costumavam rondar os centros de troca de seringas para destruí-las assim que os usuários saíam.

Esse contexto estimulou ainda mais a militância. Em 1992 foi fundada a ASUD e, em 1993, por iniciativa de Anne Coppel, foi criado o coletivo Limiter la Casse ("limitar os prejuízos"), reunindo militantes da luta contra o HIV, médicos, psicólogos e psiquiatras, além de associações, clubes de PS e ONGs humanitárias. Através de manifestos, artigos na imprensa e colóquios, este coletivo pressionou pela mudança nas políticas públicas. Segundo Coppel, foi num destes colóquios que, em 1993 e por sua "culpa", o termo "risco" passou a ser utilizado no contexto da prevenção:

Tivemos um colóquio (Triville), mas não tínhamos a palavra. Havia harm reduction, e não sabíamos como traduzir. Então decidimos: 'Vamos traduzir por redução de riscos', mas na verdade harm não é risco. Achamos que seria melhor para a comunicação. Porque 'danos' não é bonito. Para mim, harm são os riscos e os danos. Na verdade, trata-se de limitar as consequências nocivas ligadas ao uso de drogas (...) Fui eu que traduzi mal harm, voilà. Mas, do ponto de vista da comunicação, funcionou bem. (Coppel, 2016)

Tal estratégia comunicativa encontrou ouvidos em Simone Veil, política francesa famosa pela militância por causas sociais, na época ministra de Assuntos Sociais, Saúde e Cidade. Em 1994, ela torna a "redução de riscos infecciosos entre usuários de drogas" um dispositivo nacional, com dois objetivos: prevenir infecções e dar acesso ao sistema público de saúde. O dispositivo compreendia programas de troca de seringas, centros de acolhimento e tratamentos de substituição de opiáceos. A redução de riscos aparecia pela primeira vez como política pública na França. ${ }^{10}$

Em 1996, o Conselho Geral de Seine-Saint-Denis cria, sob a direção de Marguerite Arène, a Missão Departamental de Prevenção das Toxicomanias, que logo muda de nome para Missão de Prevenção de Condutas de Risco de Seine-Saint-Denis. Desta vez, era a prevenção das condutas de risco que aparecia, pela primeira vez, oficializada como política pública, buscando articular setores como ação social, saúde, educação, lazer, inserção e prevenção. Em 2002, Arène funda também a Missão de Prevenção de Toxicomanias de Paris, nos mesmos moldes da anterior, apoiando projetos como o Fêtez-Clairs, que buscava responder aos "riscos festivos" (abuso de substâncias, riscos sexuais, ao volante, auditivos etc.), apontando para a crescente diversificação do que era tratado como conduta de risco.

Em 2004, a redução de riscos entra no Código de Saúde e são criados os centros de Cuidado, Acompanhamento e Prevenção em Adictologia (CSAPAs) e os Centros de Acolhimento e Acompanhamento da Redução de Riscos para Usuários de Drogas (CAARUDs). Os CSAPAs, estruturas de caráter mais médico, oferecem atendimento de saúde e psiquiátrico, e tratamentos de substituição de opiáceos. Os CAARUDs possuem centros de convivência e acolhem os usuários mediante um mínimo de exigências: eles não podem consumir drogas no local e têm de respeitar outros usuários e a equipe. Como em outras estruturas "de baixa exigência", a abstinência não é um requisito. Oferecem informação, apoio no acesso à saúde, aos direitos e a materiais de prevenção de infecções (como seringas ou o kit-crack, com cachimbo, piteiras, filtros e creme cicatrizante).

\footnotetext{
${ }^{10}$ Este dispositivo também foi muito importante por considerar a questão do financiamento. A partir de então (e, em alguns casos, até hoje), associações de redução de riscos (como AFR e ASUD) passaram a receber parte de seu orçamento do Estado, em especial da Agência Francesa de Luta contra o SIDA.
} 
Nos anos 2000, seja pelo sucesso das ações preventivas (segundo Coppel), seja por motivos mercadológicos e geopolíticos (segundo Olivet), há um declínio do uso de drogas injetáveis, concomitante à ascensão do crack. Em 2005, a Missão de Prevenção de Condutas de Risco de Seine-Saint-Denis e a Missão de Prevenção de Toxicomanias de Paris iniciam um projeto conjunto, o Plan crack nord-est parisien. Trabalhando a partir de pesquisas etnográficas, relatos de vida de usuários e grupos de discussão com profissionais das diferentes áreas envolvidas, a intervenção teve impacto nas cenas de uso de crack da região metropolitana de Paris, ajudou a consolidar a prevenção de condutas de risco como política pública e ampliou o escopo das ações preventivas (Jamoulle e Fournié, 2007). Os profissionais perceberam que não podiam apenas tratar o "problema do crack" sem levar em conta outras dimensões existenciais dos usuários (condições sociais, sanitárias, psicológicas, familiares) e sem ver neles sujeitos integrais, que não podem ser decompostos em "problemas".

O trabalho conjunto e a conformidade com essas premissas aproximaram as duas missões. Unidas desde 2013, elas formam a Missão Metropolitana de Prevenção de Condutas de Risco (MMPCR), uma tentativa de articular institucionalmente as iniciativas e recursos de prevenção dos problemas sociais que antes estavam a cargo de diferentes instituições e organizações. Assim como a sociologia dos tráficos é frequentemente separada da sociologia dos usos (Mohammed, 2014), a abordagem das políticas públicas também era. Segundo Gaudier, a opção por reunir as missões sob o "guarda-chuva" das condutas de risco foi pragmática:

Foi por observar a realidade. Nunca temos apenas uma conduta de risco, estamos sempre engajados em várias... O consenso foi que valia mais alargar o campo de ação do que restringi-lo, e nos focarmos no conjunto. Nós nos referimos, aqui, ao "ecossistema": família, bairro, escola, o ambiente social e cultural que envolve estas condutas. É uma abordagem pragmática, não se trata de grandes teorias, é agir sobre o cotidiano, tendo em conta os ensinamentos da redução de riscos. Podemos reduzir os riscos, podemos avançar na prevenção, mesmo se você for consumidor compulsivo, mesmo se você estiver no tráfico... Sempre se pode fazer alguma coisa. (Gaudier, 2016)

A MMPCR atua sobre condutas tão diversas que, num primeiro olhar, pouco teriam em comum. Abuso de substâncias, consumo compulsivo, tráfico, transtornos alimentares e prostituição recaem todos no rótulo de condutas de risco. $\bigcirc$ que poderia haver de comum entre estas condutas?

\section{Missão: construir competências}

A MMPCR realiza formações sobre temáticas ligadas às condutas de risco; organiza momentos de trocas (debates, conferências, colóquios); efetua pesquisas-ação envolvendo o público-alvo, com o objetivo de compreender as problemáticas e divulgar "boas práticas"; e, em sua sede em Pantin, mantém um espaço em que oferece oficinas pedagógicas (ateliers d'outils) e empréstimo de materiais (publicações, jogos, dinâmicas) para profissionais desejosos de intervir preventivamente junto a seu próprio público. Participei, em 2015, de um destes ateliers. Nele, os animadores demonstraram dois tipos de ferramentas pedagógicas oferecidas pela Missão. Um primeiro é específico: são jogos, dinâmicas e encenações sobre temas como sexualidade, drogas, álcool e agressividade. O segundo tipo, de acordo com os animadores, seria mais geral e deveria ser usado en amont. ${ }^{11}$ Trata-se, segundo eles, de "reforçar as competências psicossociais do público".

Na seção anterior, afirmei que o modelo de "prevenção de condutas de risco" combina harm reduction com metodologias de desenvolvimento da autoestima e das competências psicossociais (CPS). Tais competências foram definidas pela OMS (1993:1) como "a

${ }^{11}$ Literalmente, "rio acima". Em uma tradução livre, uma prevenção que deve acontecer antes mesmo da primária. 
capacidade de uma pessoa de responder com eficácia às exigências e às dificuldades da vida cotidiana". A OMS identifica dez principais CPS, agrupadas por pares: saber resolver problemas/saber tomar decisões; ter um pensamento crítico/ter um pensamento criativo; saber se comunicar com eficácia/ser hábil nas relações interpessoais; ter consciência de si mesmo/ter empatia pelos outros; saber gerenciar o estresse/saber gerenciar as próprias emoções.

Estudos na área da psicologia (Varescon, 2014; Luis e Lamboy,2015) afirmam que as condutas de risco seriam mais frequentes quando seus protagonistas têm CPS menos desenvolvidas, ressaltando a necessidade de desenvolvê-las como alavancas para a prevenção de problemas sociais, sanitários e mentais, e tratando-as como "determinantes dos determinantes". As CPS estariam estreitamente ligadas à autoestima e às competências relacionais, que por sua vez são as duas faces da mesma moeda: relação consigo mesmo e relação com os outros (Joubert et al., 2007). Assim, devem ser estimuladas através de aprendizagens específicas, e também pautadas nas relações interpessoais cotidianas, de maneira sistêmica. No atelier d'outils foram apresentados exemplos de materiais que, teoricamente, estimulam o desenvolvimento das CPS.

Para as crianças (dois a sete anos), há uma ferramenta pedagógica chamada "Uma mala cheia de emoções", com cartas mostrando rostos com diferentes expressões: raiva, tristeza, alegria, cansaço etc. O objetivo é que as crianças reconheçam as emoções nos outros (empatia) e em si mesmas (autoconsciência). Além disso, os educadores devem estimular a reflexão e o desenvolvimento da "gestão das emoções": "Se meu amigo está com raiva, do que ele precisa? De calma. Se ele está tenso, qual atitude tomamos? O que posso fazer se meu amigo está triste?".

Há jogos de tabuleiro, encenações e atividades mais físicas, como o Esqui cooperativo, dirigido a adolescentes: um par de esquis (como os de neve) que acomodam quatro pessoas. Como os pés estão presos uns aos outros, só é possível avançar em colaboração, ou todos caem. Assim, é preciso se comunicar, construir acordos, cooperar e ter confiança nos outros e nas decisões conjuntas; isso desenvolveria capacidades relacionais e comunicativas, a autoconfiança e a confiança nos outros.

Existem muitas dinâmicas com o objetivo de desenvolver/fortalecer as CPS. Mas o interessante é que estas ferramentas sejam consideradas instrumentos de "prevenção prévia", ou en amont, que devem ser utilizadas antes de qualquer problema (ou risco) surgir. A ideia é que, se as pessoas tiverem as CPS bem desenvolvidas, estas se tornam automaticamente "as bases de uma estrutura pessoal sólida, que ajudará a lidar com qualquer conduta de risco", como me disse um profissional da AVeC (Iglesias, 2016). Ou seja, as CPS seriam fatores de proteção preventiva contra as mais diversas condutas de risco. Esta prevenção en amont não partiria de um problema dado de antemão, mas da ideia de fortalecimento de capacidades e talentos. Manuel Chambrouty (da MMPCR) afirma que, no trabalho social, é comum que os profissionais vejam as pessoas como problemas - desempregado, drogado, pobre, deficiente, idoso - e limitem sua ação exclusivamente a esses aspectos:

Muitos projetos na França giram em torno daquilo que não vai bem na pessoa, no seu comportamento... Mas eu acho que é preciso ver justamente o que vai bem com ela, trabalhar com suas qualidades, suas capacidades, mostrar que ela tem recursos, sublinhar aquilo que é positivo, e não só os fracassos e dificuldades. (Chambrouty, 2016)

Para os profissionais da MMPCR, o modelo de prevenção baseado no desenvolvimento das CPS poderia ser utilizado com qualquer público, e teria o potencial de prevenir quaisquer condutas de risco. Seria importante como prevenção en amont, mas também seria aplicável tanto como prevenção secundária (reforçar as CPS daqueles que já são propensos a condutas de risco pode evitar que tenham problemas mais sérios) quanto como terciária (para prevenir a reincidência). 
Assim, para tentar responder à pergunta do final da seção anterior, talvez o que una todas estas condutas seja a forma como os agentes percebem suas causas, e as modalidades de prevenção que podem ser aplicadas a todas elas. Existem prevenções específicas para (praticamente) cada conduta de risco, mas algumas tecnologias preventivas (outreach, técnicas de redução de riscos, reforço da autoestima e das CPS) perpassam as ações preventivas dirigidas tanto ao abuso de substâncias quanto à prostituição ou ao tráfico de drogas - ou seja, tanto às condutas que trazem riscos sanitários quanto àquelas que trazem riscos propriamente sociais. A seguir, tento descrever algumas das estratégias, técnicas e tecnologias utilizadas pelos profissionais para prevenir as condutas de risco. Na impossibilidade de fazê-lo para todas, tomo o caso do engajamento dos jovens no tráfico de drogas.

\section{Prevenção do tráfico}

Como em outros lugares do planeta, o baixo escalão do tráfico de drogas na França é composto por olheiros, vendedores, babás (que estocam armas, dinheiro e produtos em casa) e gerentes, que são, em geral, recrutados muito cedo, principalmente em periferias empobrecidas e discriminadas, com grande contingente de migrantes das antigas colônias francesas e grande concentração de problemas sociais (desigualdade, desemprego, evasão escolar, baixa qualificação profissional, problemas familiares e racismo, entre outros). Para Enrique Iglesias, da AVeC - instituição instalada em Drancy, periferia que reúne todas as características listadas acima -, tais problemas, cruzados e somados, produzem efeitos conjugados, ampliando vulnerabilidades. É o que Castel (1994) chama de "desfiliação": a precarização combinada dos vínculos familiares, trabalhistas e de cidadania, que facilitaria o aliciamento dos jovens pelo narcotráfico. Junto ao qual eles estão, é claro, sujeitos a riscos múltiplos: penais (multas, encarceramento), relativos à integridade física (dano corporal, homicídio), psicológicos (medo, insônia, stress, ansiedade) e sociais (desescolarização, degradação de relações familiares, antecedentes criminais), segundo Jamoulle e Roche, 2012. No entanto, como alertei, não podemos equiparar risco a perigo, sob pena de perdermos a dimensão volitiva e de satisfação de necessidades que pode advir destas condutas, nos impedindo de compreender o que as motiva.

Segundo Mohammed (2014), as atividades ligadas ao tráfico atraem os jovens pois permitem que encontrem um lugar em meio aos pares, no bairro, na sociedade; trazem reconhecimento social, seja através do dinheiro e do consumo, seja através da aura de poder e dominação que emanam, muitas vezes pela violência; e estimulam os jovens a "se colocarem à prova". Como afirma Serrano, profissional da MMPCR, há um caráter socializante do tráfico. Para ele, as condutas de risco "restituem sentido a trajetórias afundadas em um cotidiano monótono e, sobretudo, sem perspectivas" (Serrano, 2008, p.130). Não se trataria apenas de dinheiro. Misturam-se dimensões socioafetivas, "adrenalina", inversão de estigmas, busca de virilidade, reconhecimento e autoestima (Jamoulle e Roche, 2012). A entrada no tráfico seria a busca de um local relacional, onde procuram acesso ao consumo, emoções, relações, onde possam se construir como sujeitos reconhecidos e valorizados, no qual possam obter uma consciência mais positiva de si mesmos, alcançando, enfim, uma auto-subjetivação, mesmo que através de uma conduta de risco.

De toda forma, para os profissionais da MMPCR ou da PS, o tráfico é uma conduta de risco e deve ser tratado como tal no trabalho preventivo. Combinando diferentes tecnologias sociais (redução de riscos, inclusão social e desenvolvimento de CPS, da autoestima e do reconhecimento social) e utilizando técnicas de abordagem de rua, de atração e de "cativação de clientela", o modelo da prevenção de condutas de risco tem sido utilizado na prevenção do tráfico na periferia parisiense (Esseki, 2016). Seu princípio, assim como o da redução de riscos no abuso de substâncias, é supor que, qualquer que 
seja a situação, sempre há algo a fazer, e que é possível limitar os riscos diminuindo-os progressivamente quando suprimi-los de uma vez for muito difícil ou ilusório (Roche, 2013). Além disto, esse modelo busca retirar o foco do "problema" (seja a droga, seja o crime), centrando as intervenções no desenvolvimento de capacidades, potencialidades e talentos dos assistidos e frisando formas de superar "vulnerabilidades" e "fatores de risco" que levariam a tais problemas.

Tais intervenções preventivas são colocadas em prática na França por diversas instituições: associações, pontos de escuta, ONGs e a Proteção Judiciária da Juventude (PJJ), ${ }^{12}$ entre outras. Aqui, focarei a descrição no trabalho dos clubes de prevenção especializada (como a $\mathrm{AVeC}$ e a $\mathrm{MCV}$ ), não com o objetivo de apresentar a totalidade das iniciativas ou métodos empregados, mas sim de fornecer um vislumbre do modelo aplicado e suas relações com outras formas de prevenção.

A Prévention Spécialisée (PS) é um conjunto de associações que se instalam nas áreas designadas pelo Ministério do Interior francês como Zonas Urbanas Sensíveis (ZUS) ou de Segurança Prioritária (ZSP). Elas apresentam aos departamentos projetos de intervenção que devem incluir ações de prevenção da delinquência, de animação socioeducativa e de capacitação de jovens e famílias, entre outras. Se aprovados, recebem verbas da Ajuda Social à Infância, do Ministério da Saúde e/ou de fundos que financiam a prevenção da delinquência, de acordo com os objetivos estipulados. APS não tem mandato nominativo, mas territorial: cuidar dos "jovens em risco e em vias de marginalização" de determinado bairro. Para tanto, são encorajados uma forte presença pública, o conhecimento do território e de seus problemas, a articulação com os atores locais e o estabelecimento de um espaço de proposição e troca com os jovens (Léculée, 2006).

Os educadores especializados têm, como característica de trabalho, o fato de colocarem "o jovem em dificuldade no centro de uma relação que, para ser eficaz, deve se construir no tempo e se basear na confiança"(DASES, 2011). Tal relação começa, em geral, na rua. A ação dos educadores se inicia por um trabalho de campo paciente, regular, que permita realizar uma observação fina do bairro e da maneira como os jovens o ocupam. É nesta presença de rua, neste trabalho de outreach, que os educadores estabelecem relações não apenas com os jovens, mas com famílias, vizinhos, policiais, professores. $\bigcirc$ trabalho de rua não se limita a percorrê-las. É também ocupar os espaços públicos e os locais onde os jovens se reúnem. Os educadores da PS tentam identificar, conhecer e acompanhar os jovens "em dificuldade", buscando uma "abordagem da personalidade global dos jovens que encontram" (DASES, 2011) e levando em conta as dimensões relacionais que os envolvem, ou "o ecossistema", na definição de Gaudier. Na maioria dos casos, as equipes de prevenção criam uma relação ou vínculo com os jovens e em seguida escolhem com eles quais seriam as atividades educativas mais apropriadas. Sem mandato nominativo, dependem da livre adesão. Segundo o diretor da MCV:

\begin{abstract}
A livre adesão é a capacidade dos educadores de, no trabalho de rua, ir ao encontro dos jovens que vivem ou que estão regularmente neste território e, pouco a pouco, construir uma relação de confiança e atraí-los. E os atraímos através daquilo que chamamos "suportes educativos". Desculpas educativas, na verdade. Geralmente, são passeios e viagens. É o primeiro gancho. A ideia é partir do grupo, do lazer, mas em seguida cair para o individual e para as problemáticas. Como o jovem já estará em uma relação de confiança com o educador, em um dado momento ele vai poder lhe confiar coisas de sua história e pedir ajuda. (LeCouturier, 2016)
\end{abstract}

Para fins analíticos, podemos dividir a prevenção do tráfico realizada pela PS em prevenção en amont, primária, secundária e terciária. ${ }^{13}$ No âmbito da prevenção en amont do tráfico,

\footnotetext{
${ }^{12}$ Órgão do Ministério da Justiça francês encarregado da execução das medidas socioeducativas dirigidas a crianças e jovens em conflito com a lei.

${ }^{13}$ É notável que mesmo a Estratégia Nacional de Prevenção da Delinquência da França (France, 2013) adota este modelo dividido entre prevenção primária, secundária, terciária - o mesmo utilizado na prevenção de doenças.
} 
os métodos utilizados na PS são os mesmos utilizados para as outras condutas de risco - o que faz sentido, já que os profissionais afirmam que a prevenção através do estímulo às CPS constrói fatores de proteção contra todas. Além disso, alguns eixos gerais são sublinhados pelos educadores como essenciais para prevenir o engajamento no tráfico: informar sobre os perigos da atividade, desmistificando as lógicas da organização do tráfico local; oferecer atividades que proporcionem as sensações (a "adrenalina") que buscam no tráfico, como esportes radicais; propor atividades que levem os jovens a refletir sobre o sentido das condutas nas quais se engajam, e que permitam que percebam que têm recursos pessoais que podem usar para se valorizar de outra forma que não a transgressão; propor atividades que permitam obter recursos materiais pelo trabalho. Também existem métodos e ferramentas mais específicas de prevenção do tráfico, adaptadas ao nível de envolvimento com a atividade ilegal, seguindo a clássica divisão epidemiológica.

Na prevenção primária do tráfico, os profissionais da AVeC utilizam o jogo Papillagou para sensibilizar os jovens (onze a treze anos) sobre os riscos relacionados à atividade e os mecanismos que o tráfico usa para cativar soldados, como a promessa de ganhos fáceis, processos de endividamento material e simbólico, oferta de consumo gratuito das substâncias etc. O educador divide a turma em quatro grupos. Um deles deve se dirigir às outras crianças para oferecer balas, apresentando-as como "pastilhas que melhoram a performance" (uma embeleza, outra tira a timidez etc.); o segundo grupo deve difundir um boato; um terceiro deve refletir, a partir de imagens (dinheiro, álcool, roupas) sobre as noções de desejo e necessidade; o último grupo deve oferecer chocolates aos outros, em troca de um favor que "podem fazer mais tarde", mas sem dizer que favor seria. A seguir, os jovens são convidados a fazer conexões com situações reais. As balas evocam o consumo de drogas como forma de superar situações difíceis. O chocolate, o caso de quem é obrigado a fazer algo por se sentir "em dívida" - o que acontece, por exemplo, quando um traficante dá dinheiro a crianças para que lhe comprem comida, deixa que fiquem com o troco e, em outro momento, pede que transportem drogas ou atuem como olheiros em troca. A oposição desejo/necessidade é exemplificada pelo consumo de bens de luxo, com os quais muitos sonham, enquanto o boato relembra situações em que os jovens agem por medo do que os outros dirão.

Na prevenção secundária do tráfico, dirigida àqueles que começam a ter um envolvimento, alguns profissionais utilizam a informação como arma: sabendo como o tráfico funciona, procuram desmistificar ilusões, como o mito do dealer, segundo o qual o tráfico traria muito dinheiro muito rápido. Faz sucesso entre os profissionais da PS o estudo de um economista que analisou livros de contabilidade apreendidos com traficantes franceses, e mostrou que eles não ganham tão bem assim (Ben Lakhdar, 2012). Sua projeção mostra que, na França, existem aproximadamente mil atacadistas de Cannabis, que ganham cerca de 400 mil euros/ano; 10 mil semi-atacadistas, que ganham 56 mil euros/ano; 50 mil vendedores que ganham por volta de 7 mil euros/ano; e mais de 100 mil olheiros e aviões, que ganham 3 mil euros/ano. Como bom economista, ele incluiu na conta o tempo de inatividade (pelo clima, o policiamento) e despesas com encarceramento, advogados etc. A conclusão é que a esmagadora maioria dos "funcionários" do tráfico ganha menos que o salário mínimo francês, e não dispõe de assistência social, seguro-saúde ou direitos trabalhistas, além de correr muito mais perigo que um funcionário de fast-food.

Outros profissionais centram suas ações de prevenção secundária em um misto de metodologias de redução de riscos e de desenvolvimento das CPS. Nesta perspectiva, tentam aconselhar os jovens a não investir todo o seu tempo no tráfico e a manter atividades paralelas, com o objetivo de constituir aberturas profissionais e, sobretudo, criar possibilidades de (re)construir sua autoestima e desenvolver suas capacidades. Segundo um educador:

Meu trabalho é ajudá-los a passar do risco 3 ao risco 2, e do risco 2 ao risco 1. Vale mais ter um único pé no tráfico do que os dois. Eles frequentemente têm os dois, depois um só, depois um dedinho e, às 
vezes, mais nada. Assim como em matéria de redução de riscos ligados ao uso de drogas nos dirigimos ao usuário dizendo, "Se você puder parar de consumir, é melhor. Se não, não corra muitos riscos e faça ao menos isto ou aquilo", é possível se dirigir a um jovem implicado no tráfico e dizer "Se você puder não traficar, é melhor, mas se não pode parar, por ter dívidas, por que tem que sustentar sua família, pelo menos faça isso ou aquilo. "(Jamoulle e Roche, 2012, p.26)

Impossível não perceber a semelhança entre esta fala - e a abordagem subjacente a ela - e a citação de Anne Coppel, mencionada aqui, indicando como métodos gerados no âmbito da redução de riscos entre usuários de drogas são usados na prevenção do tráfico. Mas quais atividades teriam o potencial de desenvolver a autoestima de jovens envolvidos no narcotráfico? Em 2015, fui convidado pela MMPCR a participar de uma sessão de cinema na qual foram exibidos, com todas as pompas, três filmes realizados por jovens envolvidos com o tráfico e pequenas delinquências: Mon monde à moi, ${ }^{14}$ Génération Cité e Le casse du siècle... dans tes rêves!.

Os filmes foram concebidos, escritos, encenados, dirigidos e editados pelos jovens, com o apoio técnico de profissionais da PS. Os grupos foram identificados, abordados e convencidos a participar graças ao trabalho de outreach dos educadores de rua. Uma equipe da PS identificou um grupo de jovens envolvidos com o tráfico que gostavam de cantar rap e que queriam fazer clipes para suas canções. Esse trabalho deu origem a Mon monde à moi, que alterna os clipes com cenas inspiradas na vida dos jovens, mostrando o dilema de um rapaz que recebe propostas para trabalhar no tráfico e que sofre humilhações ao procurar emprego.

No caso de Le casse du siècle, os educadores contactaram jovens engajados no tráfico que se reuniam no parque La Villette. Fascinados pelo imaginário dos "bandidos", os jovens queriam fazer um filme sobre um assalto; mas o roteiro inicial evoluiu para o pesadelo de uma adolescente que sonha que o irmão se envolveu no crime. As cenas se alternam em um modo "radiofônico", com os jovens refletindo criticamente sobre temas como violência, polícia, a ansiedade da vida no tráfico, o consumo de drogas, o dinheiro sujo que não podem gastar e a culpa por não cumprirem as expectativas dos pais.

Diversos pontos devem ser ressaltados, como o trabalho de outreach que possibilitou a realização e o envolvimento dos jovens na elaboração das propostas e as reflexões críticas que transformaram em arte. Segundo os profissionais, nestes projetos os jovens desenvolvem muitas competências, tanto técnicas quanto relacionais, mostrando seus talentos e podendo se estruturar em torno de algo positivo. Há ainda o fato dos projetos partirem das suas preocupações, desejos e vivências; a estratégia de "baixa exigência", de não pedir abstinência nem que se ausentassem do tráfico. E, finalmente, os educadores indicam o potencial de (re)construção da autoestima propiciado pela visibilidade e o reconhecimento trazidos pelos filmes e pelas exibições. Efetivamente, na sessão que presenciei os jovens foram tratados como estrelas: tapete vermelho, discursos, aplausos e familiares orgulhosos.

Em relação à prevenção terciária, realizada junto a jovens já fortemente engajados, alguns profissionais afirmam que ela não seria de sua alçada e sim da PJJ'15 e da polícia. Outros reforçam a questão do dinheiro sujo, propondo soluções alternativas. Os profissionais da PS ajudam em procedimentos junto a órgãos públicos e na procura de formações, estágios e empregos. Neste sentido, as obras educativas (chantiers éducatifs) são uma alternativa para que consigam dinheiro legalmente. Na MCV, há chantiers de construção: os jovens são contratados temporariamente para realizar serviços de jardinagem, pintura e renovação predial. Segundo LeCouturier:

\footnotetext{
${ }^{14}$ Disponível emhttp://www.dailymotion.com/video/xtd2kb_rph-mon-monde-a-moi_shortfilms\#from=embediframe. Acesso em 4 jun. 2021

${ }^{15} \mathrm{~A}$ PJJ, além de executar medidas socioeducativas, realiza trabalhos de prevenção terciária, profissionalização e reinserção social de jovens em conflito com a lei (Esseki, 2012),
} 
Além de serem pagos e terem um contrato de trabalho (muitas vezes o primeiro), com isso eles ganham consciência de que, quando trabalhamos, temos deveres, mas também direitos. Que direitos? Nós explicamos para eles. E o que é interessante, sobre a autoestima: quando o chantier termina, há um lanche com os moradores. E isso é valorizador. Permite mostrar às pessoas que estes jovens... Sim, eles enchem o saco. Sim, podem ser violentos. Mas não são só isso! São capazes de fazer bem as coisas. E os jovens têm um retorno positivo. Às vezes, é a primeira vez que escutam um adulto dizer "Obrigado, você fez um bom trabalho". (LeCouturier, 2016)

Os chantiers são considerados pelos profissionais alavancas importantes para reconstruir a autoestima, a confiança, as relações com a economia legal e com o entorno social. Ainda no âmbito da prevenção terciária, há educadores que, no espírito da redução de riscos, aconselham a não vender drogas perto de escolas, não transportar substâncias em cavidades corporais etc. Alguns chegam a ensinar como reduzir riscos legais: na França, se você for preso por tráfico, mas for usuário da substância, sua pena pode ser menor.

Tentando minimizar os malefícios do envolvimento com o tráfico, e buscando a reintegração social, ${ }^{16}$ alguns educadores apostam na transferência de competências e "saberes práticos" adquiridos no tráfico para a economia lícita (capacidades comerciais, gerenciais, contabilidade e negociação etc.) e tentam, em acompanhamentos individuais, apontar estas competências para os jovens e, através delas, estimular processos de reintegração profissional e social (Amouche, 2010).

Assim, utilizando as técnicas e metodologias de prevenção de condutas de risco - que misturam práticas de redução de riscos com desenvolvimento das CPS e da autoestima, investimento em ações educativas e inserção profissional, atividades artísticas e esportivas que trazem reconhecimento social e visibilidade -, os profissionais da PS tentam contrabalançar a atração exercida pelo tráfico, atraindo e cativando os jovens com outras atividades que proporcionem aquilo que eles buscam no comércio ilegal.

\section{Considerações finais}

A intenção deste texto foi demonstrar como o conceito de risco (e de condutas de risco) "colonizou" o campo da prevenção dos problemas sociais na França, tornando-se uma noção eficaz na definição de políticas públicas ao ser abraçado por cientistas, militantes, profissionais e políticos, que o inscreveram no quadro institucional legítimo que construíram. Neste processo, tanto risco quanto prevenção tiveram de ser reinventados, gerando novas tecnologias sociais e metodologias de prevenção, destinadas a enfrentar riscos também novos.

Tentei descrever como uma mudança semântica aparentemente inócua (a tradução de harm como risco) teve consequências importantes no desenvolvimento das intervenções preventivas que se seguiram. De fato, a noção de "prevenção de condutas de risco" é percebida como algo menos estigmatizante que aquelas utilizadas nos programas centrados "nas drogas" ou na "delinquência", que vão de par com a incriminação de indivíduos e populações. Além disso, contribuiu para diversificar o campo de atuação da prevenção dos problemas sociais na França.

Vimos que o modelo da prevenção de condutas de risco apresenta técnicas e métodos que "migraram" do campo sanitário para o da prevenção de problemas sociais. Além das técnicas de harm reduction e da adaptação da divisão em prevenção primária, secundária e terciária, ouvi muitas vezes os profissionais mencionarem "a epidemia do crack", comparando consumo de substâncias com doença, drogas com agentes patogênicos, traficantes com vetores de contaminação e profissionais de prevenção com médicos generalistas, que encaminham os "doentes" para especialistas, de acordo com seu "diagnóstico". No rastro

\footnotetext{
${ }^{16}$ Qualquer semelhança com a definição epidemiológica da prevenção terciária, apresentada anteriormente,
} não é mera coincidência. 
desta metáfora epidêmica, as condutas de risco aparecem no discurso como anomalias ou doenças do social.

Se o discurso dos profissionais - ao sublinhar o acolhimento, a construção de vínculos, a autonomia, a negociação e a participação do público-alvo na elaboração das intervenções, propagando os ideais da harm reduction - aponta caminhos que divergem do conceito de risco para o qual alertam Douglas (1992), Rabinow (2010), Bailleau (2011) e Castel (1981; 1994), o modelo "prevenção de condutas de risco", ao mesmo tempo em que se propõe mais amplo, ao abarcar uma variedade de condutas e tratar do "sujeito integral", revela as ambiguidades, tensões e paradoxos que Fassin (2010) aponta como constitutivas das políticas públicas francesas dirigidas a populações "vulneráveis" ou "em risco". Apresentam tanto uma lógica - e uma ética - humanitária, humanista e inserida na perspectiva do cuidado, quanto uma lógica - e uma política - de gestão da precariedade, de controle e disciplina.

De um lado, os profissionais e instituições evitam interpretar os problemas desses sujeitos como definidores de sua identidade, ou como insucessos individuais, compreendendoos como sintomas de um fracasso social mais amplo, que deixa populações à margem, desamparadas e "desfiliadas". Propõem uma prevenção que não reduza as pessoas a problemas, mas que as considere como sujeitos integrais, e que funcione como fator de proteção geral contra problemas e riscos, por meio de metodologias de desenvolvimento das CPS. Tentam contrabalançar o poder de atração exercido por estas condutas com atividades que tenham o potencial de atrair e cativar os jovens, e através das quais possam desenvolver competências e mostrar talentos para obter reconhecimento e visibilidade sem ter de buscá-los em práticas delinquentes ou condutas de risco. Investindo em atividades artísticas e culturais, em aprendizados profissionais e no estímulo à reflexão crítica, estas tecnologias baseadas no desenvolvimento da autoestima e da autonomia tentam trazer aos jovens a possibilidade de se construírem como sujeitos. Trata-se de um modelo estruturado sobre a importância da subjetivação, no que converge com a hipótese trazida pela literatura sobre as condutas de risco: se uma das motivações para estes comportamentos é sua capacidade de gerar auto-subjetivação, talvez a prevenção deva, ela também, se fundar neste objetivo, estimulando formas de subjetivação alternativas.

De outro lado, estas mesmas metodologias deixam entrever uma política tecnocrática, dessubjetivadora e em direção a uma gestão psicologizante e moralizadora dos problemas sociais (por exemplo, ao investir no desenvolvimento das CPS), demonstrando uma característica excessivamente "antecipadora" (ou en amont) ao realizar intervenções cada vez mais cedo (como no caso de "Uma mala cheia de emoções", usada com crianças a partir de dois anos), numa tentação "preventivista" de controle, disciplinamento e gestão de populações julgadas mais propensas a tais condutas, mesmo sem que elas tenham se manifestado.

A intenção de evitar que comportamentos de risco se desenvolvam e criar "bases pessoais sólidas" para confrontá-los é moralmente inatacável. Mas se esta é uma abordagem orientada para aqueles que não estão envolvidos em condutas de risco (ainda), por que a prevenção en amont não é generalizada para todos? Por que as intervenções ancoradas nesta metodologia (e as instituições que as efetivam, como AVeC e MCV) são dirigidas majoritariamente às populações empobrecidas e estigmatizadas, oriundas das antigas colônias francesas, não-brancas, que habitam as regiões estatisticamente assinaladas como mais propensas a tais riscos, e codificadas pelo Ministério do Interior francês como ZSP (Zonas de Segurança Prioritária)? Remetendo o risco às CPS não-desenvolvidas, reforçam políticas de controle sobre indivíduos e populações, responsabilizando-os por sua situação. Afinal, se construir ou desenvolver competências é considerado necessário, é porque elas não estão presentes (ou tão presentes quanto se deseja) em sujeitos que são, neste processo e por extensão, considerados incompetentes - caracterização que justifica e legitima a atuação das instituições e profissionais.

Neste quadro, as metodologias de desenvolvimento das CPS figuram como representação máxima de uma política tecnocrática, vinda "de cima para baixo" (o que estaria mais 
"acima" que a OMS?), orientada a pessoas e populações sujeitas a fatores de risco, mas que não ataca as causas destes fatores. Tais políticas constituem, muitas vezes, soluções individuais ou biográficas para problemas que os próprios profissionais reconhecem como coletivos, sociais, estruturais e não internos aos sujeitos, deixando de lado a necessidade de agir sobre a dimensão estrutural do risco, deixando de integrar o contexto legal, social e econômico em políticas públicas efetivas. Assim, esta abordagem revela a maneira ambígua pela qual o risco impactou políticas públicas francesas dirigidas ao governo dos vulneráveis, constituindo tanto novas formas de prevenção, subjetivação e cuidado quanto, conforme afirma Fassin (2010:64), "modos de governo pelos quais se tenta tornar vivíveis as vidas precárias e ocultar as causas sociais de tal condição".

\section{Agradecimentos}

Agradeço a Maria Hermínia Tavares de Almeida, Juliana Caruso, Maurício Fiore, Taniele Rui, Ronaldo de Almeida, aos colegas do Programa Internacional de Pós-Doutorado do CEBRAP e as/aos pareceristas anônimas/os pelas generosas leituras, sugestões e comentários a versões anteriores do texto. Agradeço também à Fundação de Amparo à Pesquisa do Estado de São Paulo, que possibilitou a pesquisa através do processo 2017/14862-5.

\section{Bibliografia}

AMOUCHE, Malika (2010). Processus d'inscription dans l'économie de rue: quelles stratégies de prévention? Ville de Paris, Conseil Général de la Seine-Saint-Denis.

BAILLEAU, François (2011). "Prévention de la délinquance ou gestion du risque?". Les Cahiers Dynamiques, 51:6-15.

BECK, Ulrich (1992). Risk Society, Towards a New Modernity. Londres, Sage Publications. BECKER, Howard (1985). Outsiders. Paris, A. M. Metailié.

BEN LAKHDAR, Christian (2012). "L'économie du deal. Comprendre pour agir". Les Cahiers Dynamiques, 56, 3:50-57.

BENSO, Vincent (2016). Entrevista a Tiago Hyra Rodrigues. 13 dez. 2016, Paris.

BERNSTEIN, Peter (1996). Against the Gods: The Remarkable Story of Risk. Nova York, Wiley.

CASTEL, Robert (1981). La gestion des risques. De l'antipsychiatrie à l'après psychanalyse. Paris, Éditions de Minuit.

CASTEL, Robert (1994). "La dynamique des processus de marginalisation: de la vulnérabilité à la désaffiliation". Cahiers de recherche sociologique, 22: 11-27.

CAVALCANTI, Lia (2001). "De la nécessité de réinventer la prévention". Peddro, n. especial:110-115.

CHAMBROUTY, Manuel (2016). Entrevista a Tiago Hyra Rodrigues. 13 nov. 2016, Pantin.

COPPEL, Anne (2002). "Les politiques de lutte contre la drogue: le tournant de la réduction des risques". Les Cahiers de l'Actif, 310-311:11-22.

COPPEL, Anne. Entrevista a Tiago Hyra Rodrigues. 19 out. 2016, Paris.

DAGNINO, R (2014). Tecnologia social: contribuições conceituais e metodológicas. Campina Grande, EDUEPB.

DASES (2011). La prévention spécialisée à Paris, 2009-2010. Département de Paris, Bureau des activités de prévention pour la jeunesse.

DOUGLAS, Mary (1992). Risk and Blame. Essays in cultural theory. Londres, Routledge.

DOWNES, David; ROCK, Paul (1988). Understanding deviance. Oxford, Clarendon Press.

ESSEKI, Karima (2012). "Le travail éducatif auprès du mineur impliqué dans le trafic". Les Cahiers Dynamiques, 56: 58-67. 
ESSEKI, Karima (2016). "Implication du mineur dans le trafic de cannabis". Nouvelle revue de psychosociologie, 21: 49-62.

EWALD, François (1986). L'Etat providence. Paris, Grasset.

FASSIN, Didier (2010). La Raison Humanitaire. Paris, Seuil/Gallimard.

FRANCE (2013). Stratégie nationale de prévention de la délinquance 2013-2017. Comité interministériel de prévention de la délinquance, Paris.

GAUDIER, Marie Therèse (2016). Entrevista a Tiago Hyra Rodrigues. 20 nov. 2016, Pantin.

IGLESIAS, Henrique (2016). Entrevista a Tiago Hyra Rodrigues. 28 set. 2016, Drancy.

INSERM (2010). Réduction des risques infectieux chez les usagers de drogues. Paris, Éditions Inserm.

JAMOULLE, Pascale \& FOURNIE, Jean (2007). Plan crack Nord-Est parisien. Mairie de Paris.

JAMOULLE, Pascale \& ROCHE, Pierre (2012). Engagement des jeunes dans les trafics: quelle prévention? Mairie de Paris, Fórum Français pour la Sécurité Urbaine.

JESSOR, Richard (1991). "Risk Behavior in Adolescence: a psychosocial framework for understanding and action". Journal of Adolescent Health, 12: 597-605.

JOUBERT, Michel, JAMOULLE, Pascale \& SERRANO, Santiago (2007). Les conduites à risques: penser et agir la prévention. Conseil général de la Seine-Saint-Denis.

KATZ, Jack (1988). Seductions of crime. Nova York, Basic Books.

LeBRETON, David (1991). Passions du risque. Paris, Métaillé.

LeBRETON, David (2002). Conduites à risque. Des jeux de mort au jeu de vivre. Paris, PUF, Quadrige.

LeCOUTURIER, Yann (2016). Entrevista a Tiago Hyra Rodrigues. 28 set. 2016, Paris.

LÉCULÉE, Annie (2006). "Prévention spécialisée et protection de l'enfance". Journal du droit des jeunes, 253: 17-18.

LUIS, Élisabeth \& LAMBOY, Béatrice (2015). "Les compétences psychosociales: définition et état des connaissances". La Santé en Action, 431: 12-16.

MOHAMMED, Marwan (2014). L'implication des jeunes dans le trafic local des drogues. Pantin, MMPCR.

OLIVET, Fabrice (2016). Entrevista a Tiago Hyra Rodrigues. 13 set. 2016, Paris.

OMS (1993). Life skills education in schools. Genebra, Division of Mental Health.

RABINOW, Paul (2010). "L'artifice et les Lumières: de la sociobiologie à la biosocialité". Politix, 90: 21-46.

RHODES, Tim (1996). Outreach Work with Drug Users: Principles and Practice. Estrasburgo, Council of Europe.

ROCHE, Pierre (2013). "Prévenir l'implication des jeunes dans le trafic des drogues". Bref du Céreq, 306.

RODRIGUES, Tiago Hyra (2011). Tirando do crime e dando oportunidade: estratégias educacionais de prevenção das violências em duas ONGs de Florianópolis. Tese de doutoramento. UFSC, Florianópolis.

RODRIGUES, Tiago Hyra (2017). "Entre faltas e oportunidades: ONGs e prevenção da violência". Revista Brasileira de Segurança Pública, 11: 130-146.

SERRANO, Santiago (2008). "Prévention des conduites à risques et question sociale". Psychotropes, 14: 127-135.

VARESCON, Isabelle (2014). "Les consomations à risque chez les jeunes: facteurs de protection et de vulnérabilité". La santé en action, 429: 24-26.

WIEVIORKA, Michel (2012). "Du concept de sujet à celui de subjectivation/dé-subjectivation". Working Paper, Paris, FMSH. 